\title{
Diagnóstico e tratamento da Porfiria Aguda: relato de caso
}

Gabriela Parreira Bizinoto ${ }^{1}$ Ygor Alexandre Lins Mourão ${ }^{1}$ Mariana de Gregório Faria ${ }^{1}$ Flávia Gomes de Campos ${ }^{2}$

1. Médicos Residentes de Clínica Médica do Hospital Regional de Sobradinho

2. Médica Assistente da Unidade de Clínica Médica do Hospital Regional de Sobradinho. Especialista em Dermatologia e Clínica Médica

E-mail para correspondência: amgabrielapb@gmail.com

\section{RESUMO}

Objetivo: Reportar o quadro clínico de uma paciente internada no Hospital Regional de Sobradinho (HRS) com o diagnóstico de porfiria intermitente aguda

Relato do caso: Paciente feminina, 28 anos, com queixa de dor abdominal e sintomas neurológicos de início agudo, e exames laboratoriais evidenciando hiponatremia grave e transaminases hepáticas elevadas

Conclusão: Na porfiria intermitente aguda, uma anamnese completa, associada a sinais, sintomas e exames laboratoriais, permite diagnóstico e tratamento mais precoces, evitando assim a evolução para um prognóstico muitas vezes desastroso

Palavras-chave: abdômen agudo, hiponatremia, porfiria, ácido delta-aminolevulínico e porfobilinogênio

\section{Diagnosis and treatment of Acute Porphyria: case report}

\begin{abstract}
Objective: Report the clinical condition of a patient admitted at the Hospital Regional de Sobradinho (HRS) with acute intermittent porphyria

Case report: Woman, 28 years old, complaining of abdominal pain and acute neurological symptoms, in addition to laboratory tests showing severe hyponatremia and elevated transaminase levels Conclusion: Performing a complete anamnesis, associated with signs, symptoms and laboratory tests, may allow an earlier diagnosis and treatment in order to prevent the evolving to a poor prognosis
\end{abstract}

Key Words: acute abdomen, hyponatremia, porphyria, delta aminolevulinic acid and porphobilinogen

\section{INTRODUÇÃO}


As porfirias consistem em deficiências enzimáticas na biossíntese do grupo heme da cadeia de hemoglobina1. São patologias incomuns e potencialmente graves se não diagnosticadas precocemente ${ }^{2}$, podendo ter causa genética ou também adquirida, e o seu diagnóstico pode ser difícil devido à sobreposição de sintomas e achados laboratoriais, consistindo em um desafio diagnóstico . O paciente com porfiria pode apresentar dores abdominais, alterações hematológicas e neurológicas ${ }^{3}$. O tratamento consiste em uso de medicamentos específicos, quando necessário, controle dos sintomas e medidas comportamentais para prevenir novas crises ${ }^{4}$. A porfiria intermitente aguda (PIA) consiste em uma causa genética, rara e autossômica dominante de baixa penetrância² .

\section{OBJETIVO}

Relatar o caso clínico, diagnóstico e tratamento da porfiria intermitente aguda, sendo ela um diagnóstico diferencial raro de abdômen agudo.

\section{RELATO DO CASO}

J.S.D, gênero feminino, 28 anos, procedente de Sobradinho - Distrito Federal, inicialmente atendida pela Cirurgia Geral com relato de síncope no dia 28/04/2019, seguida de queda da própria altura, contusão craniana e crise convulsiva com liberação de esfíncter vesical, associados a alucinações visuais e agressividade após recobrar a consciência, segundo relato da acompanhante. Três dias antes de procurar atendimento, iniciou quadro de dor em flanco e fossa ilíaca direitos, tipo pontada, sem irradiação, associada a constipação intestinal há 01 semana, disúria e dificuldade para urinar. Referiu ainda febre aferida, mas não sabia quantificar, além de restrição calórica há cerca de 02 meses. A data da última menstruação coincidiu com o dia da internação. Ao exame físico, apresentava distensão abdominal, hipertimpanismo e dor difusa à palpação. Realizou tomografia computadorizada (TC) de crânio sem alterações identificáveis ao método e tomografia computadorizada de abdômen que mostrou distensão discreta e difusa de cólons, sem evidência de pontos de obstrução, sendo descartadas condutas cirúrgicas. Ultrassonografia transvaginal (USTV) 
não mostrou alterações significativas. Exames laboratoriais da admissão evidenciaram transaminase glutâmico-oxalacética (TGO): 623 U/L, transaminase glutâmico-pirúvica (TGP): 213 U/L, sódio (Na): $114 \mathrm{mEq} / \mathrm{L}$, sorologias para hepatites B e C: negativas. A paciente persistiu com dor abdominal, hiponatremia refratária à reposição venosa de sódio e crises convulsivas, evoluindo com nistagmo horizontal após última crise e hipoacusia.

Após uma semana de internação, pela coexistência de sintomas iniciados no período menstrual, restrição calórica, alteração da dinâmica urinária e ausência de outras causas orgânicas ou externas que justificassem a coexistência de sintomas neurológicos e abdominais, foi aventada a hipótese diagnóstica de porfiria. Durante visita familiar, a prima da paciente informou, quando questionada, casos de porfiria na família com quadros clínicos semelhantes ao da paciente.

Em uma primeira ocasião, solicitou-se pesquisa do porfobilinogênio urinário com resultado positivo. Iniciou-se então tratamento com suporte glicêmico venoso, $400 \mathrm{mg} / \mathrm{dia}$, além da manutenção de reposição de sódio em bomba de infusão contínua. A paciente apresentou melhora importante dos sintomas não sendo necessário o uso de hematina na ocasião. Recebeu alta para acompanhamento ambulatorial com a hematologia. Nos exames após alta, apresentou porfobilinogênio quantitativo urinário (urina $24 \mathrm{hr}$ ): 26,22 mg/24 h (VR: inferior a $2 \mathrm{mg} / 24 \mathrm{~h}$ ), ácido delta amino levulínico (urina $24 \mathrm{~h}$ ): $16 \mathrm{mg} / \mathrm{g}$ creatinina (VR: até $4.5 \mathrm{mg} / \mathrm{g}$ creatinina), coproporfirinas (fezes): positivo (VR: negativo).

\section{DISCUSSÃO}

A Porfiria Intermitente Aguda (PIA) é uma doença autossômica dominante de baixa penetrância que ocorre pela deficiência parcial de porfobilinogênio desaminase (PBGD), que consiste na terceira via biossintética do heme ${ }^{5}$. O heme é importante para a função de diversas proteínas, incluindo hemoglobina e enzimas do citocromo P450 hepático, sendo que, em pacientes com PIA, o fígado é a fonte de superprodução da via heme, e os sistemas nervoso central, periférico, autonômico 
e entérico são prejudicados quando esses níveis intermediários estão aumentados na circulação, o que sugere neurotoxicidade ${ }^{6}$

Os sintomas da PIA ocorrem, geralmente, na puberdade surgindo de forma aguda em dias a semanas, tendo como gatilhos o uso de álcool, tabaco, stress, restrição alimentar, infecções ou certos medicamentos (barbitúricos, anticonvulsivasntes, bloqueadores de canais de cálcio, antifúngicos, antibióticos), podendo o paciente apresentar taquicardia, hipertensão, urina com cor escura, dor abdominal, náuseas, vômitos e manifestações neurológicas ${ }^{4}$.

O exame mais rápido é o qualitativo da urina (teste de Watson-Schwartz), que consiste em reagir uma amostra fresca de urina com reagentes que alteram a sua cor quando há a presença do porfobilinogênio ${ }^{3}$.

O diagnóstico definitivo consiste no encontro em amostra urinária de precursores das porfirinas: ácido delta-aminolevulínico (ALA) e porfobilinogênio (PBG), sendo que esses precursores podem mudar de cor quando expostos ao sol, de amarelo claro para tons de marrom escuro $^{2}$. As concentrações de ALA $(25-100 \mathrm{mg} / \mathrm{d})^{1}$ na urina não possuem seus níveis tão elevados quanto do PBG (50-200mg/d) ${ }^{1}$, e a porfirina fecal pode estar normal ou ligeiramente aumentada ${ }^{6}$. Níveis elevados de PBG urinários são altamente sensíveis e específicos para quadros de PIA e suficientes para se iniciar o tratamento ${ }^{5}$. Além disso, o teste genético pode confirmar a anormalidade no gene causador da PIA ${ }^{4}$. A mutação no gene da PBG deaminase possui $95 \%$ de sensibilidade e $100 \%$ de especificidade${ }^{1}$.

Em relação ao tratamento, é indicada a administração da hematina na dose de 3-4mg/dia, em 30 minutos, intravenosa, em quadros agudos com necessidade de internação hospitalar quando o paciente apresenta náuseas, vômitos, paresias, convulsões, psicose, agitação ou hiponatremia, com o intuito de repor o produto final da via produtora de heme, recuperando a função fisiológica celular, além de reduzir a produção excessiva de porfirinas ${ }^{5}$. Na ausência de hematina, a reposição de glicose 300-400 g/dia deve ser realizada, inibindo os níveis da enzima ALA sintetase e consequentemente a produção de metabólicos tóxicos da cadeia metabólica ${ }^{7}$. 
O controle dos sintomas é feito com medicamentos sintomáticos, sempre com precaução em não se administrar medicamentos porfirinogênicos, que podem desencadear ou piorar a crise aguda ${ }^{3}$. O diagnóstico e tratamento precoce podem evitar complicações como convulsões, dores crônicas, hipertensão, ansiedade e insônia, paresia ou paralisia causada pela disfunção do neurônio motor, ocorrendo especialmente em ataques agudos prolongados, que pode levar à falência da musculatura respiratória com necessidade de ventilação mecânica invasiva ou até mesmo à morte ${ }^{5}$.

\section{CONCLUSÕES}

A porfiria intermitente aguda é ainda muito sub diagnosticada pois, além de rara, se apresenta com uma gama de sinais e sintomas inespecíficos, levando o médico assistente a pensar em outros prováveis diagnósticos diferenciais de abdômen agudo ou causas neuropáticas e neuropsiquiátricas, mais comuns em nosso meio. O conhecimento da porfiria pela equipe médica, uma melhor compreensão da doença, além de uma boa história clínica e valorização dos sintomas, podem contribuir para um diagnóstico mais rápido e, consequentemente, a salvar a vida do paciente, ou evitar sequelas crônicas que possam inviabilizar sua produtividade futura.

\section{REFERÊNCIAS BIBLIOGRÁFICAS}

1. Dinardo Cl, et al. Porfirias: quadro clínico, diagnóstico e tratamento. Rev Med (São Paulo). 2010 abr.-jun.;89(2):106-14

2. Lopes DA, et al. Porfiria aguda intermitente: relato de caso e revisão da literatura. Rev Bras Ter Intensiva. 2008; 20(4): 429-434

3. Associação Brasileira de Porfiria (ABRAPO). http://www.porfiria.org.br/fac_aguda.htm / Acesso: $11 / 10 / 19,10: 49$

4. Patient education: Acute intermittent porphyria (The Basics) - UpToDate, May 15, 2019

5. Gagan KS, et al. Acute intermittent porphyria: Management - UpToDate, May 15, 2019 
6. Gagan KS, et al. Acute intermittent porphyria: Pathogenesis, clinical features, and diagnosis UpToDate, May 15, 2019

7. Porfirias agudas - Condutas na crise aguda. Hospital das Clínicas da Faculdade de Medicina de Ribeirão Preto da Universidade de São Paulo. Serviço de Genética Médica 